\title{
Artificial Intelligence Applications in the New Model of Logistics Development Based on Wireless Communication Technology
}

\author{
Shuaiqi Wang (iD \\ School of Transportation, Southeast University, Nanjing 211189, China \\ Correspondence should be addressed to Shuaiqi Wang; wangshuaiqiuk@163.com
}

Received 3 September 2021; Accepted 10 October 2021; Published 27 October 2021

Academic Editor: Punit Gupta

Copyright (c) 2021 Shuaiqi Wang. This is an open access article distributed under the Creative Commons Attribution License, which permits unrestricted use, distribution, and reproduction in any medium, provided the original work is properly cited.

\begin{abstract}
With the continuous development of artificial intelligence technology, the supply chain logistics industry has shown new changes. The products of the intelligent era such as smart devices, big data computing, and Internet of Things technology have gradually become the transformation and innovation of logistics and supply chain enterprises. The important driving force of the logistics and supply chain industry will greatly improve the operational efficiency of the logistics and supply chain industry. Methods. This article studies the technical framework of artificial intelligence and explores the upgrading and transformation of supply chain logistics enterprises in logistics infrastructure, production tools, and logistics operation processes under the promotion of artificial intelligence technology, from warehouse location, inventory management, warehousing operations, transportation, and distribution. The data analysis and prediction analyze the impact of artificial intelligence on the supply chain logistics field and finally point out the problems in the intelligent development of the supply chain logistics field and put forward targeted suggestions to promote the modern supply chain logistics to become more intelligent. developThe new development trend of smart logistics is towards sharing economy, automation, service efficiency, and cost reduction. Results. In this context, if logistics companies want to achieve higherquality development, they cannot do without business model innovation and larger-scale collaboration, transparency of logistics information, and more comprehensive information sharing. The new trend of the development of smart logistics is to develop in the direction of sharing economy, automation, service efficiency, and cost reduction. Conclusion. Intelligence and the Internet of Things are the inevitable trend of the development of smart logistics, which is mainly realized through the Internet of Things path in terms of visual information technology, intelligent robot operation, vehicle scheduling, and cargo traceability.
\end{abstract}

\section{Introduction}

In 2015, the government pointed out in the "Internet +" strategy that it is necessary to give full play to the optimization and integration role of the Internet in the allocation of production factors, deeply integrate the Internet and various fields of the economy and society, and enhance the innovation power of all fields of society. This strategic orientation accelerates the application of modern smart logistics information technology in China, and the overall development trend of the domestic and foreign logistics markets continues to improve, which has promoted the service integration demand of the logistics industry [1].

Affected by factors such as environment, terrain, and history, the development of the logistics industry varies from place to place [2]. Traditional logistics companies manage all kinds of small areas and are relatively small in scale. They cannot connect the entire logistics map. Therefore, how to realize the improvement of smart logistics integration capabilities and explore a new model of logistics development under the "Internet + " has become a key issue that needs to be resolved in the current industry. The impact of the Internet of Things on logistics will also be comprehensive. The revolutionary innovation of logistics information technology, the agile and intelligent supply chain transformation, the real-time traceable product distribution network, the traceable source of medicine and food, and so on all represent the era of smart logistics.

Under the background of "Internet +" in the new era, a new round of scientific and technological revolution has begun. It has promoted the in-depth integration of the Internet and the logistics industry. The introduction of 
information systems has changed the logistics, transportation, and warehousing links from no information exchange to communicative, and queryable smart logistics has also promoted the informatization and standardization of logistics networks to promote information sharing and interconnected communication [3]. The concept of smart logistics makes logistics people pay more attention to the balance of various logistics links, the optimization of logistics costs and logistics services in overall planning, and the use of modern information technology and functional equipment. The background of "Internet + " in the new era has become China's logistics. As a new driving force and opportunity for the high-quality development of enterprises, it is believed that under the development of information technology innovation, logistics enterprises will enter a new era of modernization and intelligence more quickly. And this article mainly discusses the new model of logistics development under the background of the Internet and modern logistics.

The application of artificial intelligence technology has a certain impact on the core competitiveness of logistics enterprises.

Influence. Hu Yue et al. (2020) based on AMOS software and structural equation model constructed "Artificial Intelligence+" from the three aspects of capital, human resources, and knowledge management [4-6]. The results of the study show that manual intelligent technology capital is the core competence that influences logistics enterprises based on artificial intelligence technology. Among them, the level of big data processing is the biggest factor affecting competitiveness. Human resources and knowledge management will also have a greater impact on the core competitiveness of logistics enterprises. The big impact is only slightly inferior to artificial intelligence technology capital.

\section{Prospects and Innovations of the Logistics Industry Development under the Background of "Internet +"}

With the development of science and technology and the mature Internet technology every day, there are more and more people online; at the same time, this model has also increased. People can carry out various activities through various modes such as online shopping. At present, people can buy goods without going out because of the increase in the number of express delivery and the rapid development of express delivery logistics systems. According to the China Logistics Data Information Center, China's total social logistics reached 229.7 trillion yuan in 2016 and 252.8 trillion yuan in 2017. Since 2010, the compound growth rate has been $10.53 \%$, indicating the development of the logistics system. However, the current logistics system cannot meet people's expectations, so continuous intelligence transformation is required. Therefore, this is an important development trend in the world today. Consider the development of science and technology in the logistics industry, as well as logistics systems. Facing the increasingly severe trend of the information age, the logistics industry has applied the data model in the large-scale development process to enhance the construction of smart logistics, accelerate the efficiency of logistics system construction, improve the logistics level, and provide more satisfactory services to consumers [7].

\section{Disadvantages Existing in Today's Logistics Industry}

3.1. Incomplete Policies for Smart Logistics Industry. At present, China's laws and regulations on the development of smart logistics are not perfect, and it is difficult to provide guarantees for the development of logistics enterprises from the legal and policy levels. As a result, the independent development model of smart logistics has problems with high difficulties and major obstacles, in terms of legality and disputes. There are major hidden dangers. The problem of disorder and disorder in the logistics market still exists, and there is an urgent need for relevant national administrative units to formulate planning standards to create a highquality environment for smart logistics for enterprises.

\subsection{Decentralized Management and Contact Evacuation.} Affected by factors such as environment, topography, and history, the development of the logistics industry varies from place to place. Traditional logistics companies manage various small areas and are relatively small in scale. They cannot make full use of the interconnection of the entire logistics landscape. A new type of logistics enterprise developed by science and technology, [8] due to excessive reliance on "Internet +", lacks relevant logistics experience, and logistics is a collective development industry, interconnected with each other; the two do not have good communication due to their own shortcomings. Lack of management experience cannot form a complete logistics industry network [9].

\subsection{Lack of High-End Professionals with Logistics Concepts.} Analyzed from the current number and quality of employees in the logistics industry, the industry lacks high-quality comprehensive logistics talents who understand that logistics business and communicate information technology, high-end professionals, and many small- and medium-sized logistics companies have limited investment capabilities and lack smart logistics technology operations. The new hardware equipment restricts the development of China's smart logistics. Although some large logistics companies have realized the application of smart logistics technology, they are still in the exploratory stage, and the concept of smart logistics has not yet been fully implemented, for the construction of logistics innovative talent training plan. For the management major under the Internet + background, a total of 500 questionnaires were issued to logistics management students and 415 valid questionnaires were restored. According to the questionnaire survey, the proportion of participating students is shown in Figure 1, and the gender ratio is shown in Figure 2. 


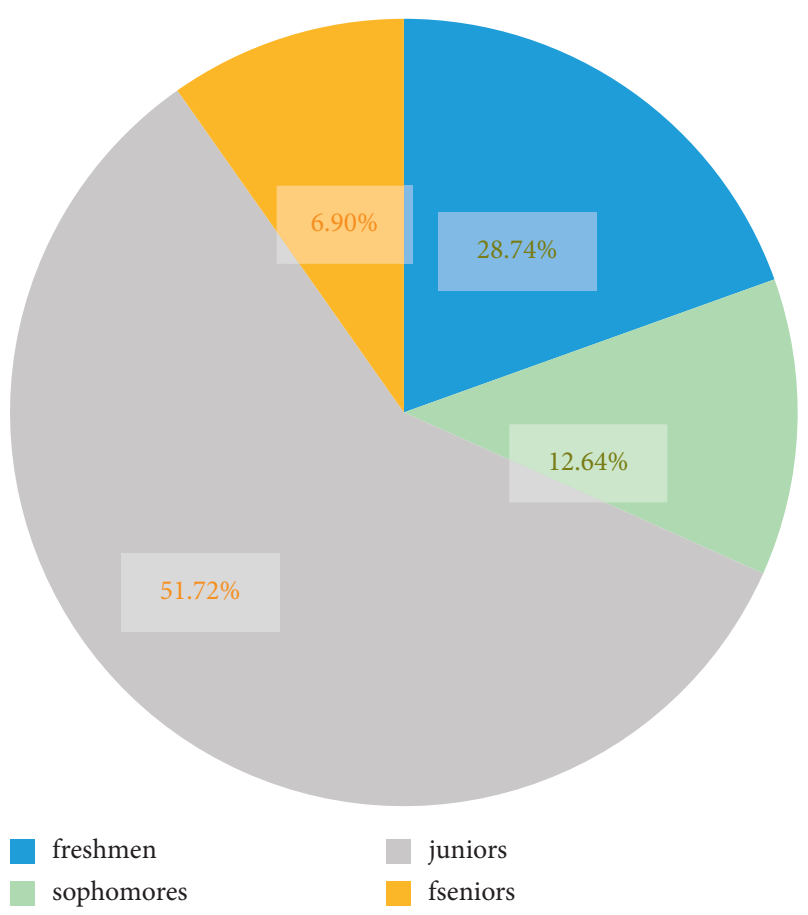

FIGURE 1: The proportion of students participating in the survey.

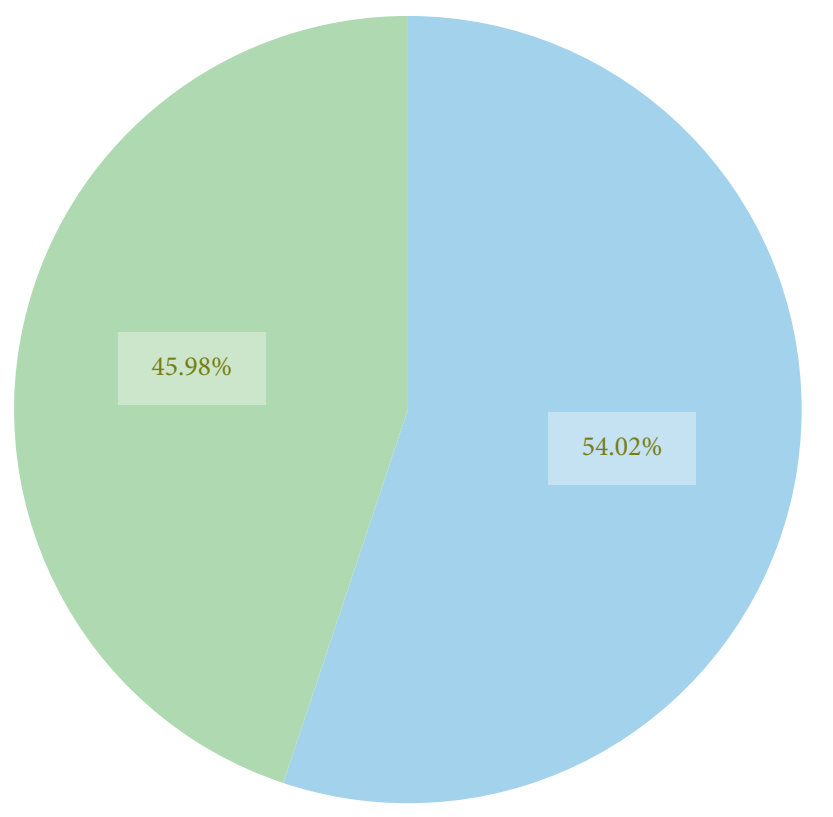

female students

male students

Figure 2: Gender ratio of students participating in the survey.

It can be seen from Figure 1 that among the students participating in the survey, $28.74 \%$ are freshmen, $12.64 \%$ are sophomores, $51.72 \%$ are juniors, and $6.9 \%$ are seniors. It can be seen from Figure 2 that the survey shows that boys account for $54.02 \%$ and girls account for $45.98 \%$. Among the 415 valid questionnaires, $7.95 \%$ of the students were not satisfied with the courses provided by their current majors.
The main reasons for their dissatisfaction are as follows: lack of technical courses; curriculum coverage is too wide, messy but not ideal; some courses offered are not related to majors; serious deviation from society; and so on.

3.4. There Are Also Many Constraints in the Development of Rural Logistics. The main disadvantages in the application of Internet information technology are the following three points. First, the rural logistics-related information platform has not been built and perfected, and some e-commerce logistics practitioners in rural areas have insufficient knowledge of network information, resulting in a lack of advanced information processing in rural logistics. With the support of transmission technology and management mode, the development of rural logistics is slow. Second, due to the fact that some rural areas, especially remote mountain villages, have not yet achieved network coverage and the logistics and transportation system is not sound, the advantages of Internet information technology are difficult to use, and there will be detours and secondary distribution during distribution, resulting in rural logistics timeliness. The poor performance also increases the cost of distribution. Third, due to the relatively slow development of China's Internet of Things, logistics, and information technology applications, the development of the e-commerce logistics industry is relatively lagging in the development of talents in China's Internet of Things, logistics, and information technology applications. However, due to the remoteness and backwardness of rural areas, relevant technical talents are extremely lacking, and most of the employees are less educated. The number of nonprofessionals also makes it difficult for Internet technology to truly play its due role in the rural logistics industry.

\section{The Direction of Logistics Development under "Internet +"}

4.1. Enterprises Leverage the "Internet +Logistics" Model. The integration, optimization, and configuration of social resources are realized through the establishment of information platforms, the sharing of logistics information is realized, the added value of logistics is increased, and the logistics interoperability between enterprises and industries is strengthened, thereby optimizing the operation mode of logistics enterprises and improving operating efficiency and profits [10-12]. The emergence of multi-industry linkage has also accelerated the development of logistics enterprises. Multi-industry linkage development can achieve resource integration and coordinated development between industries. It is an important means for the logistics industry and other industries to achieve a win-win situation and is related to the sustainability of national economic development [13-15]. It is also related to local economic growth. The development of enterprise logistics needs to be bigger and stronger, not just by doing it alone but also by cooperating with other enterprises in the supply chain. This is the advantage of the "Internet + logistics" operation model. For example, companies can unite with other companies in the supply chain through 
"Internet + manufacturers," "Internet +Suppliers," "Internet + channel providers," and so on to establish a common development model, establish mutually beneficial policies, and achieve common benefits. The base is strong.

4.2. Development of Rural Logistics. Modern logistics is highly dependent on Internet information technology. In view of the insufficiency of informatization in the development of rural logistics, rural areas should speed up the construction of logistics information platforms so that agricultural product sellers can grasp market information and sales channels in time, and production is marketable. Logistics development informatization can improve quality. And it also enables rural e-commerce logistics practitioners to implement effective supervision of logistics transportation, warehousing, distribution, and other links through the information platform terminal, which improves logistics efficiency while reducing cargo damage rate, greatly improving the service level of rural logistics, thereby accelerating construction of rural logistics information platform.

4.3. The Logistics Operation Mechanism Is Getting Better and Better. The difference between the "Internet + logistics" operation mode and the traditional logistics operation mode is not only its high efficiency and speed in information processing but also to a large extent that it is basically in a transparent state in terms of information processing. For materials, not only the sender can see the transportation status of the materials but the recipients and even some competitors can also see the transportation status of the materials through the network platform. The logistics and transportation work of enterprises is under the supervision of many eyes. Therefore, if an enterprise wants to satisfy its customers with its services and keep its customers from being snatched by competitors, it must improve the traditional logistics operation mechanism, so that the eyes of multiparty surveillance are impeccable.

4.4. Create a Green Logistics System. The green logistics system mainly includes green procurement, green processing, green packaging, green transportation, green warehousing, and green distribution. Logistics companies start to purchase equipment that has no impact on the environment. They should not blindly focus on how much they invest. They should be advocated by the state. The main purpose of the concept of environmental protection is to phase out old transportation vehicles that pollute the environment and purchase new vehicles, especially to encourage the use of energy-saving and environmentally friendly vehicles. The application of these methods can reduce the overall energy consumption of the logistics industry, and the use of new energy greatly reduces pollution, the total emission. The location of the logistics center should be set up in the links that must be stopped during transportation, such as shortdistance road transportation to the airport, air transportation must be reloaded, appropriate circulation processing in the logistics center, and combined processing and distribution measures. In order to reduce the overall operating cost of logistics enterprises, the frequency of using standardized equipment is increased such as containers and pallets during transportation, which can improve the level of logistics handling and save transportation time. Constructing a green logistics base, realizing the sharing of vehicle information among various logistics enterprises, and the joint deployment of vehicles can improve the utilization rate of vehicles, reduce the consumption of vehicles in the operation process, save fuel and materials, and protect the environment. Logistics companies should focus on building high-standard, multifunctional automated three-dimensional warehouses, focus on improving the informatization level of storage facilities and equipment, effectively integrate the resources of various companies, and build energy-saving green warehouses with environmental protection as the starting point. The branches established by the logistics company are integrated at various locations to establish a common distribution site, and a unified distribution or common distribution logistics distribution model is adopted at the logistics distribution site to fully and efficiently mobilize the original limited distribution vehicles and redo route planning and personnel deployment, which can save resources and unnecessary waste to the greatest extent.

\section{Conclusion}

The logistics industry, as a stimulating industry under the background of the Internet + era, must always take the national development plan as the prerequisite for its own development, look to the future, start from the perspectives of theoretical basis, technological improvement, and social development, and establish a logistics industry suitable for the development of logistics industry. As an important technical resource in the twenty-first century, artificial intelligence can provide supply chain logistics with technical support that integrates big data, cloud computing, and the Internet of things. Artificial intelligence is a powerful driving force for the transformation of the logistics industry. For supply chain logistics companies, they should follow the current trend of intelligent development in all walks of life, vigorously promote the transformation of logistics infrastructure and production tools to intelligent, realize the construction of supply chain logistics operation processes in the direction of intelligence, and at the same time realize the supply chain resource sharing and sound system standards, increase the training of artificial intelligence professionals, and promote the integration and coordinated development of artificial intelligence and supply chain logistics.

\section{Data Availability}

Data sharing is not applicable to this article as no datasets were generated or analyzed during the current study. 


\section{Conflicts of Interest}

The author declares that there are no conflicts of interest with respect to the research, authorship, and/or publication of this article.

\section{References}

[1] L. Zheng, "Jiangsu smart logistics enhances logistics integration capability under "Internet+" research on countermeasures," Logistics Engineering and Management, vol. 42, no. 8, pp. 21-24, 2020.

[2] A. Geetha and C. Subramani, "An idea for students project work: energy management in hybridization of energy sources for transportation application," International Journal of Electrical Engineering Education, vol. 57, no. 3, pp. 253-271, 2020.

[3] S. Wang and Z. Yang, "Research on the construction of smart logistics development system," Business Economy Research, no. 23, pp. 90-91, 2018.

[4] N. Liu and Z. Dou, "Talking about the letter of intelligent logistics warehousing in the $5 \mathrm{G}$ era information development," Logistics Engineering and Management, vol. 4, no. 41, pp. 25-29, 2019.

[5] X. Liu, "The transformation and upgrading of logistics enterprises in the era of artificial intelligence development trend," Business and Economic Research, vol. 3, no. 4, pp. 1-10, 2019.

[6] H. Han, "The impact and difference of artificial intelligence technology on the efficiency of the logistics industry analysis," Business and Economic Research, vol. 2, no. 22, pp. 33-42, 2020.

[7] Z. Xin-yong, "The realization of wisdom physical logistics based on the internet of things," Journal of Changzhou Institute of Technology, vol. 24, no. 5, pp. 46-48, 2011.

[8] Y. Pan, Research on the Impact of Information Intervention on Internet Logistics Information Platform Users' Intention to Adopt Research, Zhejiang Gongshang University, Hangzhou, China, 2015.

[9] H. Zhao, "The support body of my country's smart logistics development under the background of "Internet +" department research," Journal of Changchun Normal University (Humanities and Social Sciences Edition), vol. 39, no. 3, pp. 65-67, 2020.

[10] R. Xu, C. Wang, X. Luo, and J. Li, "Based on the background of "internet + " research on deep intelligence of logistics real estate," Logistics Technology, vol. 40, no. 3, pp. 7-11, 2017.

[11] X. Wang, J. Zhou, and Y. Gu, "Smart logistics deployment in the context of new retail model study: taking ali hema xiansheng as an example," Logistics Engineering and Management $L i$, vol. 42 , no. 1 , pp. 22-25, 2020.

[12] X. Lan, "Thinking and practice in the era of intelligent logistics in the "Internet +" supply chain," Modern Business, no. 8, pp. 26-27, 2020.

[13] H. Wang, X.-M. Zhang, G. Tomiyoshi et al., "Association of serum levels of antibodies against MMP1, CBX1, and CBX5 with transient ischemic attack and cerebral infarction," Oncotarget, vol. 9, no. 5, pp. 5600-5613, 2017.

[14] J. Yao, L. Wang, K. Liu et al., "Evaluation of electrical characteristics of biological tissue with electrical impedance spectroscopy," Electrophoresis, vol. 41, no. 16-17, pp. 1425-1432, 2020.

[15] W. Gaihua, Z. Tianlun, D. Yingying, L. Jinheng, and C. Lei, “A serial-parallel self-attention network joint with multi-scale dilated convolution," IEEE Access, vol. 9, no. 5, pp. 71909-71919, 2021. 